\title{
Recent Advances in Researches on Shrimp Immune Pathway Involved in White Spot Syndrome Virus Genes Regulation
}

\section{Yihong Chen ${ }^{1}$, Xiaoyun $\mathrm{Li}^{2}$ and Jianguo $\mathrm{He}^{1,2 *}$}

${ }^{1}$ MOE Key Laboratory of Aquatic Product Safety/State Key Laboratory for Biocontrol, School of Marine Sciences, Sun Yat-sen University, 135 Xingang Road West, Guangzhou 510275, P. R. China

${ }^{2}$ School of Life Sciences, Sun Yat-sen University, 135 Xingang Road West, Guangzhou 510275, P. R. China

\begin{abstract}
Shrimp is an important aquaculture species. Litopenaeus vannamei, Fenneropenaeus chinensis, Marsupenaeus japonicus, and Penaeus monodon are the main cultivated species in the world. The yield of shrimp culture was about $3,130,000$ tons in the year 2013. Though shrimp industry has been made great progress in the last decade, shrimp diseases still endangering the healthy development of this industry. On the one hand, occurring of shrimp disease was the result of kinds of pathogenic microorganism infection, such as WSSV. On the other hand, environmental stress also played an important role in disease outbreak. Researchers have paid more attention to the shrimp immune system, and mechanism of environmental stress responding nowadays. Shrimp immune system, including physical barriers, cellular immunity and humoral immunity, was important for shrimp to combat diseases. Among these, humoral immunity was the most well studied. Currently, the main pathways of the shrimp immune system, including TLRs pathway, IMD pathway, JAK-STAT pathway, RNAi pathway, P38 MAPK pathway, and JNK pathway have been proved to play important roles in shrimp immunity. Meanwhile, shrimp unfolded protein response (UPR) was considered to be the core of its environmental stress resistance system. In addition to ATF6 pathway, the other two branches of UPR, the IRE1-XBP1 pathway and PERK-elF2 $\alpha$ pathway have been shown to exist, and took effect in shrimp environmental stress responding. These studies also revealed a secret of WSSV: it activated and used a number of immune pathways as well as the UPR of shrimp, to increase its genes replication. This review intends to present the latest development in shrimp innate immunity, UPR, and their regulation on WSSV. It will also help us to understand the relationship between shrimp humoral immune response/UPR and WSSV infection.
\end{abstract}

Keywords: Shrimp immunity; Humoral immunity; Environmental stress; Unfolded protein response; WSSV

\section{Introduction}

There are two significant systems for internal homeostasis protection of invertebrate, the innate immunity system and the environmental stress responding system, which worked together to protect cells from biotic and abiotic stresses. In response to pathogen infection, the host innate immune system activated microbial clearing pathways and cellular stress relief pathways that needed to be balanced for insufficient or excessive immune responses leading to deleterious consequences. Shrimp is an invertebrate with open circulatory system, especially prone to alter in the environmental change. In addition, as an aquatic livestock, shrimp exposed to temperature shifts, viral infections, sudden salinity changes, and heavy metal toxicity, as well as various pathogens, which may interfered with shrimp internal homeostasis. In most cases, the innate immunity system and UPR helped to against these pathogens, while sometimes they worked on the contrary $[1,2]$.

Immune responses are typically distinguished in two main systems, the adaptive and the innate immune response. Shrimp seems to just rely on the innate immune system, which refers to the evolutionary ancient and presumably conserved first-line host defense against the early phases of microbial infection. It is believed that it recognized broadly conserved microbial moieties, and defense against pathogens. Humoral immune response is a vital part of shrimp innate immunity system. It is mainly containing blood cells (hemocytes), which floating in the hemolymph participates in phagocytosis and encapsulation of foreign invaders, for example, some components of shrimp blood cells asked for melanization. The larval fat body, a functional analog of the mammalian liver and the main larval energy reservoir, is the chief site of the shrimp larva's humoral (or systemic) immune response, while in adults other tissues can take on major roles for immune surveillance
[3]. Beside, shrimp has physical barriers (exoskeleton, chitinous epithelial lining of gut and trachea) to prevent microbial from entering into its body.

Recent studies demonstrate that living organisms have developed strategies to cope with many kinds of environmental changes. However, when confront acute changes, they suffer stresses. The main damage of stresses for living organisms is protein denaturation. In other words, these proteins lose their native, functional configuration. The metabolism and function of hemocytes, which are significant part of defense in marine invertebrates, must be adaptable to the changing ambient conditions for survives. Therefore, stress responses may play a more direct role in the immune function of hemocytes besides insuring survival. Unfolded protein response (UPR), initiated in endoplasmic reticulum stress (ER-stress), is a mechanism that eukaryotic cells using to cope with stresses [4]. It is a cascade of responses against the accumulation of unfolded or misfolded proteins in the lumen of the ER. This mechanism is highly conserved and has been observed in all mammalian species, as well as in worms and yeasts [5,6]. UPR contributes to cell survival during ER-stress by enhancing the protein folding capacity in the ER [7]. In most species, three well-characterized

*Corresponding author: Jianguo He, School of Life Sciences, Sun Yat-sen University, 135 Xingang Road West, Guangzhou 510275, P.R. China, Tel: +86-2039332988; Fax: +86-20-39332849; E-mail: Isshjg@mail.sysu.edu.cn

Received March 01, 2014; Accepted March 26, 2014; Published April 17, 2014

Citation: Chen Y, Li X, He J (2014) Recent Advances in Researches on Shrimp Immune Pathway Involved in White Spot Syndrome Virus Genes Regulation. J Aquac Res Development 5: 228 doi:10.4172/2155-9546.1000228

Copyright: (๑) 2014 Chen Y, et al. This is an open-access article distributed under the terms of the Creative Commons Attribution License, which permits unrestricted use, distribution, and reproduction in any medium, provided the original author and source are credited. 
pathways are involved in UPR [8-10]. Each pathway contains a class of transmembrane ER-resident signaling components, named inositolrequiring enzyme 1 (IRE1), double-stranded RNA-activated protein kinase (PKR)-like ER kinase (PERK), and activating transcription factor 6 (ATF6) [11]. The response to ER-stress is mediated at the transcriptional and translational levels $[12,13]$. In mammals, the transcriptional activation of UPR-responsive genes is regulated by two distinct pathways, the ATF6 pathway and the IRE1-XBP1 pathway. The PERK-eIF2 $\alpha$ pathway mainly works at translational level [14]. UPR inhibits protein translation to restore normal cell functions, activates the signaling pathways to increase the production of molecular chaperones involved in protein folding, also activates the signaling pathways that result in the targeting of misfolded proteins in the ER for ubiquitination and subsequent degradation by proteasomes [15]. When ER-stress is not relieved, UPR results in apoptosis [16-19].

\section{Shrimp Humoral Immune Response}

\section{Toll like receptors (TLRs) pathway}

In Drosophila, Toll pathway mainly contains Spätzle, Tolllike receptors (TLRs), Pelle, SARM, Tollip, Tube, MyD88, TRAF6, Cactus, Dorsal, and Dorsal-related immunity factor (DIF) [20]. It is involved in Gram-positive bacteria and fungi responding by leading signaling cascades, and regulating some immune-relative genes, such as antimicrobial peptide (AMPs), lysozymes as well as components of the melanization and clotting cascades. Both shrimp and Drosophila are arthropod, and they have similar TLRs pathway. Nowadays, most components of the TLRs pathway have been discovered in shrimp, and studying about them proved essentials to our understanding of this pathway in shrimp (Table 1).

TLRs: So far, all investigated species have more than one TLR. TLRs, which are receptors that could recognize pathogen-associated molecular pattern (PAMP) derived from microbes, play a key role in the innate immune system. Once the microbes breached physical barriers, such as the shell or intestinal tract mucosa, TLRs could recognize them and activate the antimicrobial response [21]. In penaeid shrimp, several types of TLRs were isolated. The first TLR gene (designated as LvToll) encoding 926 amino acid residues was reported in L. vannamei [22]. It contains an extracellular domain containing 16 leucine-rich repeats (LRRs) flanked by cysteine-rich motifs and a cytoplasmic Toll/ interleukin-1 receptor (TIR) domain. The TIR domain showed high similarity to Apis mellifera Toll and Drosophila melanogaster Toll, with $59.9 \%$ and $54.3 \%$ identity respectively [22]. Another study showed that knock-down LvToll does not increase mortality after challenge with white spot syndrome virus (WSSV) $[23,24]$. Recently, two TLRs (LvToll2 and LvToll3) were isolated from L. vannamei. LvToll2 has 1009 amino acid residues with an extracellular domain containing 18 LRRs and a cytoplasmic TIR domain of 139 residues. 1244 residues with an extracellular domain containing 23 LRRs and a cytoplasmic TIR domain of 138 residues constitute of LvToll3, which was localized to the membrane and cytoplasm like LvToll, while LvToll2 was confined to the cytoplasm. LvToll2 but not LvToll or LvToll3 could significantly activate the promoters of AMPs, which were controlled by NF- $\kappa B$ pathway. In the gill, they were all up-regulated with WSSV challenge [25].

A TLR in Penaeus monodon (PmToll, accession NO. ADK55066) shows 59\% similarity to a Toll-related protein of Apis mellifera. LRRs of PmToll contained no obvious PAMP-binding insertions. Phylogenetic analysis with the insect TLRs family show it clustering with Toll1 and Toll5, and it is less related to Toll3 and Toll4.
Furthermore, RT-qPCR shows that PmToll is constitutively expressed in gut, gill and hepatopancreas, and challenge with WSSV shows equal levels of expression in these organs [26]. Counterpart of LvToll in Fenneropenaeus chinensis (FcToll, accession NO. EF407561) also be cloned, and it showed similar characteristic and function with LvToll [27]. There were also two TLRs in Marsupenaeus japonicus (MjToll, accession NO. BAF99007; MjToll2, accession NO. BAG68890) as reported [28].

Spätzle: In Drosophila, Spätzle (Spz) was upstream of Toll, and roled in both the embryonic development and innate immune response [29]. In the dorsal-ventral pattern development of embryonic or as a pro-Spz processing enzyme in immune response, $\mathrm{Spz}$ is cleaved by a serine protease Easter, and then activated. Gram-positive bacteria or fungi could induce a protease cascade to activate the pro-Spz, and resulted in production of AMPs in adult flies [30]. It has been reported that three Spz-like proteins (LvSpz1 3) were cloned from $L$. vannamei [25]. All these Spz-like proteins have a putative C-terminal cysteine-knot domain. LvSpz1 and LvSpz3 in gill were up-regulated after WSSV challenge, but LvSpz2 showed no obvious change [25]. From hemocytes of Fenneropenaeus chinensis, a Spz-like protein ( $\mathrm{FcSpz}$ ) was isolated too. It consisted of $997 \mathrm{bp}$ with an ORF of 768 $\mathrm{bp}$, which encoded a protein of 255 amino acids with a signal peptide of 19 residues. FcSpz was up-regulated in shrimp after challenging with WSSV. The recombinant protein of FcSpz C-terminal active domain could upregulate the expression of crustin in crayfish [31]. These results suggested that shrimp Spz might play a role in the innate immune defense.

Pelle: Downstream of the activated TLRs, MyD88-Tube-Pelle form a heterotrimeric complex via their death domains (DD) [32]. Activation of Pelle leads to cascade reaction, which results in degradation of Cactus (the homolog of mammalian IkB). After that, NF- $\mathrm{kB}$ family protein Dorsal is released and gets into the nucleus for the transcriptional induction of immune-related genes [33]. The cDNA of $L$. vannamei Pelle (designated as LvPelle) consists of $1706 \mathrm{bp}$ nucleotide with an ORF of 1611 bp encoding 537 amino acid residues. The LvPelle genome is $8031 \mathrm{bp}$ containing eight exons and nine introns. It contains an $\mathrm{N}$-terminal death domains and a C-terminal protein kinase domain, showing $24 \sim 40 \%$ identity with IRAK family proteins from insect to human. LvPelle death domain consists of six a-helices, which is similar to Drosophila Pelle and mouse IRAK4. It was constitutively expressed in different tissues of shrimp and showed different expression profiles in tissues when shrimp was infected by WSSV or bacteria [1]. LvPelle localized in the cytoplasm of S2 cells, which was consistent with the putative function of LvPelle in forming a receptor complex with MyD88 and Tube.

TRAF6: Tumor necrosis factor receptor (TNFR)-associated factor 6 (TRAF6), a key signaling adaptor protein for the TNFR superfamily and the Interleukin-1 receptor/Toll-like receptor (IL-1/TLR) superfamily, is the down-stream target of Pelle [34,35]. Full-length cDNA of L. vannamei TRAF6 (named LvTRAF6) was 2823 bp long, with an ORF encoding a putative protein of 594 amino acid residues. It constitutively expressed in various tissues, and could activate the promoters of AMPs. With V. alginolyticus or WSSV challenge, the expression of LvTRAF6 was changed. This indicated that LvTRAF6 might play a crucial role in antibacterial and antiviral responses through regulated AMPs [36].

Dorsal: Dorsal is a Rel/NF- $\kappa \mathrm{B}$ transcription factor, which is activated in the successive signaling cascade of TLRs pathway for antifungal and antibacterial responses [37]. Dorsal homolog was cloned 
Citation: Chen Y, Li X, He J (2014) Recent Advances in Researches on Shrimp Immune Pathway Involved in White Spot Syndrome Virus Genes Regulation. J Aquac Res Development 5: 228 doi:10.4172/2155-9546.1000228

Page 3 of 13

\begin{tabular}{|c|c|c|c|c|c|c|}
\hline \multirow[t]{2}{*}{ Component } & \multirow[t]{2}{*}{ Species } & \multirow[t]{2}{*}{ Gene name } & \multirow[t]{2}{*}{ Accession number } & \multicolumn{2}{|c|}{ Tissues: variation at transcription level } & \multirow[t]{2}{*}{ References } \\
\hline & & & & Response to bacteria & Response to WSSV & \\
\hline \multirow[t]{6}{*}{ Toll } & L. vannamei & LvToll & DQ923424.1 & G: up & G: up & [22] \\
\hline & L. vannamei & LvToll2 & JN180637.1 & G: none & G: up & [25] \\
\hline & L. vannamei & LvToll3 & JN180638.1 & G: none & G: up & [25] \\
\hline & F. chinensis & FcToll & EF407561.1 & L: modulated & L: down & {$[125]$} \\
\hline & M. japonicus & MjToll1 & BAF99007 & I & I & [28] \\
\hline & M. japonicus & MjToll2 & BAG68890 & I & I & Unpublished \\
\hline \multirow[t]{5}{*}{ Spätzle } & L. vannamei & LvSpz1 & JN180646.1 & G: up & G: up & [25] \\
\hline & L. vannamei & LvSpz2 & JN180647.1 & G: down & G: none & [25] \\
\hline & L. vannamei & LvSpz3 & JN180648.1 & G: up & G: up & [25] \\
\hline & \multirow[t]{2}{*}{ F. chinensis } & \multirow[t]{2}{*}{ Fc-Spz } & \multirow[t]{2}{*}{ I } & G, Hc, Hp, I, & G, Hc, Hp, I, & [31] \\
\hline & & & & Ht:up & $\mathrm{Ht}:$ up & \\
\hline \multirow[t]{3}{*}{ Pelle } & \multirow[t]{3}{*}{ L. vannamei } & \multirow[t]{3}{*}{ LvPelle } & \multirow[t]{3}{*}{ JN180645.1 } & G:none; & G: up; & [1] \\
\hline & & & & I:down; & Hp, I: down & \\
\hline & & & & Hp:modulate; & & \\
\hline TRAF6 & L. vannamei & LvTRAF6 & HM581680.1 & G, Hp: none; & G, Hp: up; & [36] \\
\hline & & & & I: down & I: down & \\
\hline Dorsal & L. vannamei & LvDorsal & FJ998202.1 & I & I & [39] \\
\hline & F. chinensis & FcDorsal & EU815056.1 & L, Hc: up & L, Hc: & [38] \\
\hline & & & & & modulated & \\
\hline SARM & L. vannamei & LvSARM & JN185615. & I, Hp: none; & I, Hp: none; & [46] \\
\hline & & & & Hc:down; & & \\
\hline & & & & G: up; & G, Hc: up; & \\
\hline Tillip & L. vannamei & LvTillip & JN185616 & I, Hc: down; & Hp: none; & [47] \\
\hline & & & & Hp:none; & G, Hc, I: up; & \\
\hline & & & & & M:modulated & \\
\hline IMD & L. vannamei & LvIMD & FJ592176.1 & Hc, Hp: up; & Hp, G: none; & {$[50]$} \\
\hline & & & & G: none & Hc: up & \\
\hline Relish & L. vannamei & LvRelish & FJ416145.1 & 1 & 1 & [54] \\
\hline & L. vannamei & sLvRelish & FJ416146.1 & I & I & \\
\hline & F. chinensis & FcRelish & EU815055.1 & Hc: down; & Hc: modulate; & [53] \\
\hline & & & & L:modulated & L: up & \\
\hline IKK & L. vannamei & LvIKK $\beta$ & AEK86518 & I, G, Hp: up & I, G: up & [55] \\
\hline & L. vannamei & LvlKKE & AEK86519 & G, Hp: up; & G, Hp, Hc: up & \\
\hline & & & & Hc: dowm; & & \\
\hline & & & & I: modulated & & \\
\hline STAT & L. vannamei & LvSTAT & HQ228176 & I & I & [57] \\
\hline & P. monodon & PmSTAT (L) & EU367985 & I & I & Unpublished \\
\hline & P. monodon & PmSTAT & AY327491 & I & Ce: down & [2] \\
\hline & M. japonicus & MjSTAT & AB501344 & I & 1 & Unpublished \\
\hline P38 & L. vannamei & Lvp38 & JX990130 & G: up & 1 & [78] \\
\hline Dicer1 & L. vannamei & LvDcr1 & EU676241 & I & Hc, G: up & [69] \\
\hline & P. monodon & PmDcr1 & EF446324 & I & HI: none & [68] \\
\hline & M. japonicus & MjDcr1 & GU265733 & I & I & Unpublished \\
\hline Dicer2 & L. vannamei & LvDcr2 & HQ541163 & I & G: up & [70] \\
\hline & P. monodon & PmDcr2 & JX624789 & Hp: up & Hp: up & [71] \\
\hline & M. japonicus & MjDicer2 & AFB82635 & 1 & I & Unpublished \\
\hline Ago & L. vannamei & Lv-Ago1 & ADK25180.1 & I & I & [126] \\
\hline & P. monodon & PmAgo1 & DQ663629 & I & I & [65] \\
\hline & M. japonicus & MjAgo1A & FJ593185 & 1 & L, Hp: up & [64] \\
\hline & M. japonicus & MjAgo1B & FJ593186 & I & L, Hp: up & [64] \\
\hline & M. japonicus & MjAgo1C & JX170715 & I & I & [64] \\
\hline & L. vannamei & Lv-Ago2 & HM234690.1 & 1 & 1 & {$[126]$} \\
\hline & P. monodon & PmAgo3 & JX845575 & 1 & 1 & [65] \\
\hline TRBP & F. chinensis & Fc-TRBP1 & EU679001 & Hc, S, G, I, & Ht, G, I: up; & [72] \\
\hline & & & & Ht, Hp: up; & Hc, Hp:down & \\
\hline & F. chinensis & Fc-TRBP2 & EU679001.1 & Hc, S, G, I, & Ht, G, I: up; & [72] \\
\hline & & & & Ht, Hp: up; & Hc, Hp: down & \\
\hline & F. chinensis & Fc-TRBP3 & FJ573168.1 & Hc, S, G, I, & Ht, G, I: up; & [72] \\
\hline & & & & Ht, Hp: up; & $\mathrm{Hc}, \mathrm{Hp}$ : down & \\
\hline
\end{tabular}




\begin{tabular}{|c|c|c|c|c|c|c|}
\hline & L. vannamei & LvTRBP1 & HQ541157 & I & I & [70] \\
\hline & L. vannamei & LvTRBP2 & 1 & I & I & Unpublished \\
\hline & L. vannamei & LvTRBP3 & 1 & I & I & Unpublished \\
\hline & P. monodon & PmTRBP1 & JX465430 & Hp: up & Hp: up & [74] \\
\hline Drosha & M. japonicus & MjDrosha & JQ918355 & I & L: up & [127] \\
\hline Ars2 & L. vannamei & LvArs2 & HQ692888 & I & I & [76] \\
\hline Pasha & L. vannamei & LvPasha & HQ692889 & I & I & {$[76]$} \\
\hline SID1 & L. vannamei & Lv-SID1 & HM234688.1 & I & I & [126] \\
\hline
\end{tabular}

Note: Ce, Cephalothoraces; G, gill; Hp, hepatopancreas; Hc, hemocytes; Ht, heart; HI, Hemolymph; I, intestine; L, lymphoid organ; M, muscle; S, stomach; up, differentially up-regulated; down, differentially down-regulated; modulated, different regulation trends at different post-infection time; none, no obvious difference; /, not available

Table 1: P38 mitogen-activated protein kinases (MAPKs).

from $F$. chinensis (designated as FcDorsal) and L. vannamei (named LvDorsal). ORFs of FcDorsal and LvDorsal encoded 357 amino acid residues and 400 amino acid residues, respectively. And both of them contained a Rel homolog domain (RHD) and an IPT/TIG (Ig-like, plex-ins and transcription factors) domain. FcDorsal had the highest expression level in the hemocytes and lymphoid organ (Oka), and its expression profiles in hemocytes and lymphoid organ were apparently modulated when shrimp were stimulated by bacteria or WSSV. Knockdown of FcDorsal by dsRNA led to the decrease of the transcription of pen5 [38]. And for LvDorsal, dual-luciferase reporter assays indicated that LvDorsal could trans-activate the pen 4 and Drosophila Atta [39].

Cactus: NF- $\kappa B$ pathways play important roles in innate immune response, and I $\mathrm{KB}$ is the main cytoplasmic inhibitor of this pathway [40]. Drosophila Cactus inhibited dorsal from binding DNA [40]. $L$. vannamei Cactus (LvCactus) contained six predicted ankyrin repeats, which was the same as those from insects. LvCactus localized in cytoplasm and interacted with L. vannamei Dorsal. Over-expression of LvCactus appeared downregulated the activities of shrimp AMP promoters. Promoter of LvCactus was predicted to contain five putative NF- $\kappa \mathrm{B}$ binding motifs, and four of them were proved to be bound by LvDorsal. LvCactus was promoted by LvDorsal and inhibited by LvCactus itself, which indicating a feedback regulatory pathway between LvCactus and LvDorsal. LvCactus was up-regulated after Lipopolysaccharides, poly (I:C), V. parahaemolyticus, and Staphylococcus aureus injections, suggesting an activation response of LvCactus to bacterial and immune stimulant challenges. On the contrary, expression of LvCactus was inhibited by WSSV. It is possible that WSSV modified the feedback regulatory pathway of LvCactus/ LvDorsal during infection [41].

Cactus also was cloned in F. chinensis. Genomic DNA sequence of FcCactus was more than 17698 bp, included seven exons and six introns. Spatial expression profiles showed that FcCactus mRNA had the highest expression level in muscle, hemocytes, heart and lymphoid organ. Gram-positive bacteria (Micrococcus lysodeikticus) and Gram-negative bacteria ( $V$. anguillarium) injection to shrimp caused the modulation of FcCactus at the transcription level. Knockdown FcCactus by dsRNA showed that FcCactus could regulate the expression of different AMPs and antiviral factor (AV) [42]. These data showed that Cactus might play a critical role in regulating the immune response of shrimp.

Myeloid differentiation factor 88: Myeloid differentiation factor 88 (MyD88) is a universal and pivotal adapter protein in IL-1/ TLR mediated NF- $\mathrm{KB}$ pathway activation [43]. Two MyD88 protein variants (LvMyD88 and LvMyD88-1) were identified in L. vannamei. LvMyD88 cDNA was 1848 bp in length and contained an ORF of 1428 bp; LvMyD88-1 cDNA was 1719 bp in length and had an ORF of 1299 bp. Both variants encoded proteins with DD and TLR/interleukin-1 receptor (IL-1R)-related (TIR) domain and shared 91\% sequence identity. In healthy L. vannamei, the LvMyD88 was highly expressed in hemocytes, and with a low level in the hepatopancreas. LvMyD88s were induced in hemocytes after challenge with lipopolysaccharide, CpG-ODN2006, V. parahaemolyticus, S. aureus, and WSSV, but not by poly I:C. Overexpression of LvMyD88s in Drosophila S2 cells led to activation of AMPs and wsv069 (ie1), wsv303, and wsv371 [44].

MyD88 homolog from F. chinensis (FcMyD88) was 477 amino acids with a DD and TIR domain. The expression level of FcMyD88 mRNA was significantly up-regulated at 1 hour (h), $12 \mathrm{~h}$ and $24 \mathrm{~h}$ with both V. anguillarum and M. lysodeikticu. The expression level of FcMyD88 was 2-fold up-regulated at $12 \mathrm{~h}$ post injection (hpi) of inactivated $V$. anguillarum, while it did not change after M. lysodeikticu injection during this period. After WSSV injection, the expression level of FcMyD88 mRNA remained relatively constant, and the FcMyD88 protein was significantly up-regulated at 12 and 24 hpi [45]. These results suggested that MyD88 might take part in antibacterial and antiviral response in shrimp.

Sterile-alpha and armadillo motif-containing protein (SARM) and Toll-interacting protein (Tollip): Over-activation of TLRs pathway may leads to severe damage to the host, such as in chronic inflammatory diseases and cancer, therefore this pathway need tightly controlled. And in mammals, SARM negatively regulated TLRs pathway. L. vannamei SARM (LvSARM) shared signature domains with and exhibited significant similarities to mammalian SARM. Expression of LvSARM was responsive to $V$. alginolyticus and WSSV infections in the hemocytes, gill, hepatopancreas and intestine. In Drosophila S2 cells, LvSARM significantly inhibited the promoters of the NF$\mathrm{kB}$ pathway-controlled AMPs, and silencing LvSARM increased the expression levels of PENs and anti-LPS factors, while it was strange that mortality rate was increased after $V$. alginolyticus infection. These results revealed that LvSARM might be a novel component of the shrimp Toll pathway, which negatively regulated shrimp AMPs [46].

Tollip is another important factor for negative regulation TLRs pathway in mammalian. L. vannamei Tollip (LvTollip) shared significant similarities to mammalian Tollips, and contained a centrally localized protein kinase $\mathrm{C}$ conserved region 2 (C2) domain and a C-terminal CUE domain. Expression levels of LvTollip were altered in the gill, hemocytes, hepatopancreas, intestine, and muscle tissues after challenges with WSSV or $V$. alginolyticus. LvTollip significantly inhibited the promoter activities of the NF- $\mathrm{KB}$ pathway-controlled pen 4 in Drosophila S2 cells. Knock-down LvTollip increased the expression level of pen4. While the mortality rate of LvTollip-knockdown shrimp in response to WSSV or $V$. alginolyticus infections was not significantly different from those of the control group [47].

\section{Immune deficiency (IMD) pathway}

IMD: IMD pathway is the vital signaling cascades which regulate 
the expression of AMPs in Drosophila [48]. IMD and Relish are the two key components of this pathway (Table 1). IMD preferentially recognizes Gram-negative bacteria, and its mutation showed severe defects in resistance to Gram-negative bacteria but has normal response to fungi and Gram-positive bacteria [49].

Full-length cDNA of L. vannamei IMD (LvIMD) was 758 bp with an ORF of $483 \mathrm{bp}$ encoding a putative protein of 160 amino acids including a DD at the C-terminus. LvIMD showed similarity to that of Drosophila IMD and human receptor interacting protein 1 (RIP1) of the TNFR pathway, respectively. LvIMD mRNA expressed in most tissues and was induced in hepatopancreas and hemocytes after immune challenge. Luciferase reporter assays confirmed that LvIMD was able to induce the expression of AMPs [50]. The above data indicated that LvIMD participated in innate signaling to activate the expression of AMPs in L. vannamei.

Relish: Relish is triggered by the IMD pathway in response to infection by Gram-negative bacteria [51]. Stimulation results in the Relish N-terminal RHD and C-terminal ANKs cleaved. Then RHD translocates into the nucleus and induces the expression of AMPs [51,52]. The full length cDNA of F. chinensis Relish (FcRelish) consisted of $2157 \mathrm{bp}$, including a 1512 bp ORF, encoding 504 amino acids. FcRelish was highest expression in the hemocytes and lymphoid organ. Its expression was affected by $V$. anguillarium and M. lysodeikticus stimulation. Silencing FcRelish through RNAi greatly changed the transcription profile of AMPs [53]. And in L. vannamei, two full length cDNAs of Relish homolog (designated LvRelish and sLvRelish) were obtained. Long form LvRelish with an ORF encoding 1207 amino acids, contained a conserved RHD, a nucleus localization signal, an IкB-like domain (six ankyrin repeats), and a DD. The short form LvRelish (sLvRelish) cDNA was 1051 bp encoding 317 amino acids. SLvRelish had the same RHD region as LvRelish. Electrophoretic mobility shift assay showed that recombinant RHD of LvRelish in S2 cells bound specifically to $D$. melanogaster NF- $\mathrm{KB}$ motifs in vitro. Furthermore, LvRelish could regulate the transcription of pen4 [54].

IKK $\beta$ and IKKع: Two IкB kinases homologs, LvIKK $\beta$ and LvIIKK $\varepsilon$ are cloned from Litopenaeus vannamei. Both of them are widely expressed in different tissues. LvIKK $\beta$ but not LvIKKe activates the promoters of NF- $\kappa B$ pathway-controlled AMPs, such as PENs in Drosophila S2 cells. While in HEK 293T cells, both of them activate an NF- $\mathrm{NB}$ reporter. Knock-down the expression of LvIKK $\beta$ or LvIKKe using sequence-specificity dsRNA decreased the expression of PENs, lysozyme and crustins in L. vannamei [55].

\section{JAK-STAT pathway}

JAK-STAT signaling pathway transmits chemical signals outside into cell nucleus, which causes DNA transcription and activity in the cells [56]. It consists of three main components: (1) a receptor (2) Janus kinase (JAK) and (3) Signal Transducer and Activator of Transcription (STAT). Except for STAT, members of this pathway have not been cloned in shrimp (Table 1).

P. monodon STAT (PmSTAT) had two isoforms, the short one with 774 amino acids, and the long one with 790 amino acids. They shared identities of $99 \%$. Alignment and comparison with the deduced amino acid sequences of other STATs identified several important conserved residues and functional domains, including the DNA binding domain, SH2 domain and C-terminal transactivation domain. Phylogenetic analysis suggested that shrimp STAT belonged to the ancient STAT family, while the presence of the functional domains suggested that shrimp STAT might share similar functions and regulating mechanisms with the well-known STATs isolated from model organisms [2]. The $L$. vannamei STAT were cloned, and its function in iel transcriptional regulation was investigated [57].

\section{RNA interference (RNAi)}

RNAi is a critical regulator of many diverse biological functions, such as transcriptional gene regulation, post-transcriptional gene silencing, heterochromatin remodeling, suppression of transposon activity, and antiviral defenses [58,59]. Nowadays, RNAi has been reported to be relatively well conserved in species of different phyla. It has been proved that there is functional RNAi system in penaeid shrimp (Table 1). Yet its immune function remains still unclear [60].

Argonaute (Ago): Argonaute (Ago) proteins are the central component of the RNAi pathway, and plays important roles in host innate antiviral immunity. Each Organism always has a large number of different Ago proteins and isoforms. Several Ago genes have been cloned in shrimp, two in L. vannamei (Lv-Ago1 and Lv-Ago2), three in P. monodon (PmAgo1, PmAgo2, and PmAgo3) and three in $M$. japonicus (MjAgo1A, MjAgo1B, and MjAgo1C) [61-65]. Shrimp Ago proteins contain a PAZ domain and a PIWI domain, which both exhibit highest homology to their counterparts in D. melanogaster [61]. Ago interacts with other proteins, such as Dicer2 or Tudor staphylococcal nuclease, and then form the RNA-induced silencing complex (RISC) [65]. It also involves in anti-viral immunity as reported [64].

Dicer: Dicer, a member of the RNase III family, catalyzes the cleavage of double-stranded RNA to small interfering RNAs (siRNAs) and microRNAs (miRNAs), and finally directs sequence-specific gene silencing [66]. Invertebrate has two dicer proteins, Dicer1 involved in miRNAs pathway, and Dicer2 involved in siRNAs pathway [67]. Both P. monodon Dicer1 (PmDcr1) and L. vannamei (LvDcr1) had an ORF $7422 \mathrm{bp}$ encoding a polypeptide of 2473 amino acids $[68,69]$. During the developmental stages from fertilized egg to postlarva VII, LvDcr1 was constitutively expressed at all examined development stages, but the expression levels varied significantly. The highest expression level was observed in fertilized eggs then decrease from fertilized egg to nauplius I stage, and the higher levels of expression were detected at nauplius $\mathrm{V}$ and postlarva stages. LvDcr1 expression regularly increased at the upper phase of nauplius, zoea and mysis stages than their prophase. The different expression of LvDcr1 in the larval stages could provide clues for understanding the early innate immunity in the process of shrimp larval development. It was suggested that both PmDcr1 and LvDcr1 took part in antiviral defense in adult shrimp [69].

Dicer2 (Dcr2) is the key protein of the siRNA pathway. The fulllength cDNA of L. vannamei Dcr2 (LvDcr2) was 5513 bp long, with an ORF encoding a putative protein of 1502 amino acids. It was demonstrated that LvDcr2, LvAgo-2, and L. vannamei transactivating response RNA-binding protein isoform 1 (LvTRBP1) interacted with each other, and formed the RISC complex. A luciferase reporter assay indicated that LvDcr2 engaged in LvSVC1, LvSVC4, LvSVC5, and DmSVC Vago (DmVago) activation, which were potential antiviral genes. LvDcr2 also be up-regulated in immune responses against Poly $(\mathrm{C}-\mathrm{G})$ or WSSV challenge. These results suggested that LvDcr2 might engage in non-specific activation of anti-viral immunity [70].

Full length cDNA of Penaeus monodon Dicer2 (designated as PmDcr2) contains a $5^{\prime}$ untranslated region (UTR) of $109 \mathrm{bp}$, an open reading frame (ORF) of $4509 \mathrm{bp}$ and a 3' UTR of $842 \mathrm{bp}$. PmDcr2 shared the highest similarity of $91.8 \%$ and $90.7 \%$ with LvDcr2 and MyDcr2, 
respectively. PmDcr2 was widely expressed in almost all examined tissues except muscle, with high expression in gill, hemocytes and lymph. The expression of PmDcr2 in hepatopancreas was up-regulated by V. vulnificus, WSSV, dsRNA poly (I:C) and ssRNA R484, but not by $S$. aureus. These data reflected that PmDcr2 was response to the gram negative bacterial infection and viral infection in black tiger shrimp [71].

TRBP1: TRBP plays an important role in many biological processes, and is a critical component of the RISC, which is a key complex in the RNAi. It is showed that TRBP1 interacts with eIF6. There were three TRBP family genes cloned from $F$. chinensis. Expression of $\mathrm{Fc}$ TRBP was detected in many tissues, with elevated expression in the heart, gill, and intestine in the early stages of infection by the WSSV, and enhanced expression in most tissues following challenge with $V$. anguillarum. The expression pattern of eIF6 was also analyzed and its expression was up-regulated in intestine of WSSV-challenged shrimp. The replication of WSSV was reduced after injection of FcTRBP. These results indicated that FCTRBP and FceIF6 might be components of the RISC, and thereby played a crucial role in the antiviral defense response of shrimp [72]. Similar function was detected in M. japonicus TRBP [73].

There also cloned three L. vannamei TRBP genes (LvTRBP1, LvTRBP2, and LvTRBP3) and a P. monodon TRBP gene (PmTRBP1). LvTRBP1 was found to interact with LvDicer2, and to form RISC [70]. PmTRBP1 was evolutionarily closest to LvTRBP1. Both of them owned three double-stranded RNA-binding motifs, a character of TRBP family. Tissue expression profile analysis showed that PmTRBP1 was with a predominant expression in the lymphatic organs and with the weakest expression in the ovaries. PmTRBP1 expression was upregulated when elicited by systemic injections of $S$. aureus, V. vulnificus, and WSSV, thereby revealing its pathogen inducibility. Furthermore, exogenous viral nucleoside analogs (dsRNA poly(I:C) as well as ssRNA R484) were remarkably induced PmTRBP1 transcription at $9 \mathrm{~h}$ and $48 \mathrm{~h}$ postinjection, respectively, which suggested that PmTRBP1 might function in tiger prawn antibacterial and antiviral response [74].

ARS2, Pasha and Drosha: It has been reported that Ars2 regulates both miRNA and siRNA dependent silencing and suppresses RNA virus infection in Drosophila [75]. The full-length cDNA of $L$. vannamei arsenite resistance gene 2 (LvArs2) was $3470 \mathrm{bp}$, including a $5^{\prime}$ untranslated region (UTR) of $167 \mathrm{bp}$, a 3' UTR of $639 \mathrm{bp}$, and an ORF of 2664 bp encoding 887 amino acid residues with an estimated molecular mass of $102.5 \mathrm{kDa}$. Co-Immunoprecipitation demonstrated that LvArs2 interacted with LvDcr2 and L. vannamei Pasha (LvPasha) in $\mathrm{S} 2$ cells, suggesting that LvArs2 might be involved in regulation of the miRNA/siRNA pathways in L. vannamei. Subcellular localization assays demonstrated that both LvArs2 and LvPasha mainly presented in the nucleus. After Poly $(C-G)$ stimulation, the expression of LvArs2 was suppressed and expression of LvPasha was enhanced in shrimp gills. These results suggested that LvArs2 and LvPasha might participate in the defense against RNA viruses in L. vannamei [76].

The RNase III Drosha is a critical component for miRNA maturation. Shrimp Drosha was characterized in M. japonicus (MjDrosha). The sequence analysis revealed that it encoded a 1081-amino-acid peptide, which comprised two tandem ribonuclease III C terminal domains and a double-stranded RNA binding motif. The MjDrosha was homologous with those of other animal species. It was highly expressed in lymphoid organ and was significantly up-regulated in response to WSSV challenge, which suggesting that MjDrosha was involved in the antiviral immunity of M. japonicus. Knock-down MjDrosha led to the defect of miRNA maturation, and subsequent higher virus loads in $M$. japonicus. Therefore, MjDrosha played important roles in the antiviral defense of M. japonicus.

\section{P38}

P38 mitogen-activated protein kinases (MAPKs) are broadly expressed in eukaryotes, from yeasts to mammals, and are involved in the regulation of responding to various extracellular stimulus [77]. It was found that p38 MAPK gene (designated as Lvp38) in $L$. vannamei contained the conserved Thr-Gly-Tyr (TGY) motif as well as the substrate-binding site, Ala-Thr-Arg-Trp (ATRW) (Table 1) [78]. Lvp38 was highest expressed in hemocytes, nerves, and intestines. It was upregulated in gills and hemocytes after infection with the $V$. alginolyticus and the $S$. aureus. It was showed that Lvp38 activated the expression of AMPs in Drosophila and shrimp. Knock-down Lvp38 resulted in a higher mortality of $L$. vannamei with $V$. alginolyticus and $S$. aureus infection, and a down regulation of shrimp AMPs pen4, crustin, and ALF2. It seems that Lvp38 roled in defending against bacterial infections.

\section{Antimicrobial peptide (AMP)}

One important products of immune response are AMPs whose primary function is killing or cleaning the infected pathogens. Their production was regulated by Toll and IMD pathway in Drosophila [79]. The penaeidins, initially characterized from the shrimp L. vannamei, are a family of antimicrobial peptides that appear to be expressed in all penaeid shrimps [80]. In shrimp the penaeidins exhibited activities against both Gram-positive and negative bacteria and fungi [81]. Antilipopolysaccharide factor (ALF), a small basic protein, was initially isolated and characterized in amebocytes of the horseshoe crab Limulus polyphenus [82]. An ALF gene cloned form hemocytes of $F$. chinensis (ALFFc) was constitutively expressed in hemocytes. In responding to Vibrio infection, ALF transcription level appeared significant enhancement [83].

Crustins also is an important AMP in shrimp. The first crustin was isolated from the granular hemocytes of the shore crab C. maenas [84]. In F. chinensis, different types of crustins were reported, and a characteristic of the crustins is containing a whey-acidic protein (WAP) domain at the C-terminal. In M. japonicus, a gene with two WAP domains (Mj-DWD) was isolated. During the early phase of WSSV infection, the Mj-DWD expression was significantly upregulated. The recombinant Mj-DWD, expressed by $P$. pastoris, showed specific protease inhibitory activity on Bacillus subtilis [85]. The above data showed that diversified crustins existed in shrimp and they seemed to have function divergence, anti-bacteria or anti-virus activity.

In summary, the members of humoral immune response make up of a fine defense in shrimp, which can respond quickly to microbial invasion. Most of them took part in antiviral defense. WSSV simulate the humoral immune response, however, WSSV could utilize immune factors to regulate viral genes expression that make the cleaning of WSSV become difficult.

\section{Shrimp UPR}

As an aquatic livestock, L. vannamei is exposed to temperature shifts, viral infections, sudden salinity changes, heavy metal toxicity and so on, which may induce ER-stress and injure it. Some genes involved in UPR, including (immunoglobulin heavy chain-binding protein) Bip, heat shock protein 70 (HSP70), heat shock protein 90 (HSP90), protein disulfide isomerase (PDI), hypoxia-inducible factor 
Citation: Chen Y, Li X, He J (2014) Recent Advances in Researches on Shrimp Immune Pathway Involved in White Spot Syndrome Virus Genes Regulation. J Aquac Res Development 5: 228 doi:10.4172/2155-9546.1000228

Page 7 of 13

(HIF), and calreticulin (CRT), have been cloned in shrimp. Their roles in the ER-stress have been studied [86-93] (Table 2). The relationship between the virus and UPR in shrimp has also been investigated. There are three branches for UPR, except ATF6 pathway, two branches have been investigated in L. vannamei.

\section{IRE1-XBP1 pathway}

The inositol-requiring enzyme-1 (IRE1)-X-box binding protein 1 (IRE1-XBP1) pathway is the main branch of the UPR [4]. Full-length cDNA of L. vannamei IRE1 (LvIRE1) was 4908 bp long, with an ORF encoding a putative 1174 amino acid protein. Full-length cDNA of L. vannamei XBP1 (LvXBP1) is 1746 bp long [94]. It contained two ORFs encoding putative 278 amino acid and 157 amino acid proteins, respectively. A predicted IRE1 splicing motifs CNG'CNGN were located within the loop regions of two short hairpins on LvXBP1
mRNA. It was interesting that the splicing fragment induced by ERstress showed a $3 \mathrm{bp}$ or $4 \mathrm{bp}$ frame shift from the predicted sites. The spliced form LvXBP1 (LvXBP1s) fused the two ORFs together, and encoded a putative 463 amino acid protein. LvXBP1s activated the promoter of important UPR effector LvBip. RT-PCR showed that LvXBP1 was spliced upon heat shock treatment or WSSV challenge. These results suggested that the IRE1-XBP1 pathway was important for L. vannamei environmental stress resistance, and L. vannamei IRE1XBP1 may be activated by WSSV and be annexed to serve the virus.

\section{PERK-eIF2 $\alpha$ pathway}

PERK-eIF2 $\alpha$ pathway is another important branch of UPR [4]. In L. vannamei immunity, PERK and eIF2astill not cloned. Yet activating transcription factor 4 (designated as LvATF4), which was the key transcription factor of PERK-eIF2a pathway, has been identified and

\begin{tabular}{|c|c|c|c|c|c|c|}
\hline \multirow[t]{2}{*}{ Component } & \multirow[t]{2}{*}{ Species } & \multirow[t]{2}{*}{ Gene name } & \multirow[t]{2}{*}{ Accession number } & \multicolumn{2}{|c|}{ Tissues: response to stress } & \multirow[t]{2}{*}{ References } \\
\hline & & & & stresses & Response & \\
\hline XBP1 & L. vannamei & LvXBP1 & JQ265944 & heat & Hc: up & {$[94]$} \\
\hline IRE1 & L. vannamei & LvIRE1 & JQ265943 & 1 & 1 & [94] \\
\hline ATF4 & L. vannamei & LvATF4 & JX908828 & WSSV & Hc : none; G: up & [94] \\
\hline \multirow[t]{17}{*}{ HSP } & L. vannamei & LvHSP60 & FJ710169. & bacterial & G, Hp, Hc: up & [98] \\
\hline & L. vannamei & LvHSP70 & EF495128 & bacterial & Hc, He: up & {$[98,100]$} \\
\hline & \multirow[t]{3}{*}{ F. chinensis } & \multirow[t]{3}{*}{ FcHSP70 } & \multirow[t]{3}{*}{ FJ167398.1 } & heat, & Ce, Ht: up (heat); & \multirow[t]{3}{*}{ [101] } \\
\hline & & & & heavy & Ce: up (Copper); & \\
\hline & & & & metal & Ce: dwom (Cadmium) & \\
\hline & P. monodon & PmHSP70 & AF474375.1 & heat & Hc: up & {$[128]$} \\
\hline & \multirow[t]{3}{*}{ F. chinensis } & \multirow[t]{3}{*}{ FcHSP90 } & \multirow[t]{3}{*}{ EF032650.1 } & \multirow[t]{3}{*}{ heat, hypoxia } & Hc, G: modulated & \multirow[t]{3}{*}{ [102] } \\
\hline & & & & & (hypoxia); & \\
\hline & & & & & W: up (heat) & \\
\hline & \multirow[t]{2}{*}{ P. monodon } & \multirow[t]{2}{*}{ PmHSP21 } & \multirow[t]{2}{*}{1} & heat, & P: up (heat); & \multirow[t]{2}{*}{ [103] } \\
\hline & & & & WSSV & P: down (WSSV) & \\
\hline & Artemia & \multirow[t]{2}{*}{ p26 } & \multirow[t]{2}{*}{ DQ310577 } & \multirow[t]{2}{*}{1} & \multirow[t]{2}{*}{1} & \multirow[t]{2}{*}{ [105] } \\
\hline & franciscana & & & & & \\
\hline & M. japonicus & MjHSP40 & AB520825 & WSSV & Hc, L: up & [106] \\
\hline & M. japonicus & MjHSP70 & AB520826 & WSSV & Hc, L: up & [106] \\
\hline & M. japonicus & MjHSP90 & AB520827 & WSSV, & Hc, L: up (WSSV ); & [106] \\
\hline & & & & heat & G: up (heat) & \\
\hline GRP78 & F. chinensis & FcGRP78 & EF032651 & heat, & Ce: up (heat); & [108] \\
\hline & & & & WSSV & Hc: down; Hp, L: up & \\
\hline & L. vannamei & LvGRP78 & JQ265942 & 1 & 1 & [94] \\
\hline CRT & P. monodon & PmCRT & JX961661.1 & heat & Hc: up; Hp,G: none & [112] \\
\hline & F. chinensis & FcCRT & DQ323054.1 & heat, & Ce: up (heat); & [111] \\
\hline & & & & WSSV & Hc, Hp: modulated & \\
\hline & & & & & (WSSV) & \\
\hline HIF & Palaemonetes & gsHIF-1a & AY655698 & hypoxic & Hp: none & [92] \\
\hline & pugio & & & & & \\
\hline & L. vannamei & LvHIF-1 $\alpha$ & FJ807918 & hypoxic & G, M, Hp: down & [91] \\
\hline & L. vannamei & LvHIF-1 $\beta$ & FJ807919 & hypoxic & G:down; M: up; & [91] \\
\hline & & & & & Hp: none & \\
\hline PDI & L. vannamei & LvPDI & FJ179395 & bacterial & Hc: up & [93] \\
\hline & P. monodon & PmPDIA6 & JF290430 & 1 & 1 & [129] \\
\hline & F. chinensis & FcPDI1 & HQ630061 & bacteria, & Hp, G: up (bacterial); & [130] \\
\hline & & & & WSSV & O: down (bacterial) & \\
\hline & F. chinensis & FcPDI2 & HQ630062 & bacteria, & Hc, Hp, G: up & [130] \\
\hline & & & & WSSV & (WSSV); & \\
\hline & & & & & O: down (WSSV) & \\
\hline
\end{tabular}

Note: Ce, Cephalothoraces; G, gill; Hp, hepatopancreas; Hc, hemocytes; Ht, heart; L, lymphoid organ; M, muscle; O, ovary; Pleopod, P; S, stomach; W, whole shrimp; up, differentially up-regulated; down, differentially down-regulated; modulated, different regulation trends at different post-infection time; none, no obvious difference; /, not available.

Table 2: Heat shock proteins (HSPs) 
characterized. The full-length cDNA of LvATF4 was 1972 bp long with an ORF 1299 bp long, encoded protein with 432 amino acids. Reporter gene assays showed that LvATF4 could upregulate the expression of WSSV gene wsv023 in an ATF/CRE-dependent manner. Knock-down LvATF4 also resulted in a lower cumulative mortality of L. vannamei under WSSV infection. Under the WSSV challenge, LvATF4 was upregulated in gills. It looks like that in L. vannamei UPR signaling pathway transcription factors were important for WSSV infection [95].

Heat shock proteins (HSPs): HSP are highly conserved proteins that are found in diverse organisms from bacteria to mammals. HSPs participate in a variety of cellular processes, such as folding or unfolding of proteins, translocation of proteins into organelles and so on [96]. HSPs have been considered as an appropriate biomarker for the measurement of stress resistance in shrimp. So far, L. vannamei hsp 60, hsp70 [97-100], F. chinensis hsp 70, hsp 90 [101,102], P. monodon hsp21, hsp70 and hsp90 [103,104], Artemia franciscana small hsp belonging to the $\alpha$-crystalline family of proteins, referred to as p26 [105]. M. japonicus hsp40, hsp 70 and hsp 90 genes [106] have been cloned, and their functions in shrimp immunity and stresses resistance have been investigated (Table 2).

GRP78: The $78 \mathrm{kDa}$ glucose-regulated protein (GRP78), also known as $\mathrm{BiP}$, is an essential regulator of ER homeostasis because of its multiple functions in protein folding, ER calcium binding, and controlling of the activation of transmembrane ER stress sensors [107]. The first reported GRP78 gene in crustacean is F. chinensis GRP78 (FcGRP78) with an ORF 1,968 bp encoding 655 amino acids. The deduced amino acid sequence of FcGRP78 shared $86 \%, 87 \%$ and $85 \%$ identity with GRP78s of D. melanogaster, A. aegypti and B. mori, respectively [108]. Heat shock at $35^{\circ} \mathrm{C}$ significantly enhanced the expression of FcGRP78 at the first hour, reached the peak value at $4 \mathrm{~h}$ post heat shock treatment, then fell back and resumed to the normal level until $48 \mathrm{~h}$ of post recovery at $25^{\circ} \mathrm{C}$. Besides, when shrimp were challenged by WSSV, differential expression levels of FcGRP78 were detected in hemocytes, hepatopancreas and lymphoid organ [88]. It was suggested that FcGRP78 might play important roles in chaperoning, protein folding and immune function of shrimp.

Calreticulin (CRT): Calcium signaling has its roles in growth, reproduction and molting in crustaceans [108]. And Calreticulin (CRT) is a main protein involved in calcium homeostasis of eukaryotes [109]. The full-length cDNA of CRT in P. monodon was $1682 \mathrm{bp}$, containing an ORF of $1221 \mathrm{bp}$ corresponding to a deduced protein of 406 amino acids. Genomic sequence of PmCRT was 3006 bp in length, composing of 4 exons and 3 introns. In hemocytes of juvenile P. monodon, PmCRT was upregulated at early stage $(0$ and $1 \mathrm{~h})$ post treatment at $35^{\circ} \mathrm{C}$ for $3 \mathrm{~h}$. But the expression levels in gills and hepatopancreas after the temperature stress $(0-48 \mathrm{hpt})$ showed no significantly difference with the control groups. Expression profile of PmCRT in hemocytes was up-regulated at 0 and $3 \mathrm{hpt}$ for about 25 fold, then reduced to about 5 fold between 3 and $12 \mathrm{hpt}$ and returned to the baseline level at 24 and $48 \mathrm{hpt}$. Furthermore, PmCRT exhibited an ability to form a complex with recombinant Endoplasmic Reticulum protein 57 of $P$. monodon (rPmERp57). F. chinensis calreticulin (FcCRT) had the same length and similar function with PmCRT. Above results suggested that shrimp CRT might work at $\mathrm{Ca}^{2+}$ homeostasis, chaperoning and immune function in shrimp [88], and be a suitable biomarker for temperature stress responses [110].

In summary, there are two pathway of UPR, IRE1-XBP1 and PERK-eIF2 $\alpha$ pathway, which have been proved to exist in shrimp. Besides helping shrimp to cope with environment stress, they involved in WSSV genes expression. The molecular chaperones (HSP70, Bip, and CRT) which are essential regulators of ER homeostasis, also relate to WSSV infection.

\section{Shrimp Humoral Immune Response and WSSV Genes Regulation}

The host responding to the pathogens helps to clean pathogenic microorganisms. For successful infection, pathogens developed strategies to evade these responding, even to use them. As the most dangerous pathogens for shrimp, WSSV could benefit from the host responding in several ways.

\section{Shrimp TLR-Dorsal pathway upregulated expression of WSSV ie1, wsv303 and wsv371}

The immediate-early gene iel of WSSV expresses highly throughout the infection cycle, and exhibits very strong promoter activity [111] A NF- $\kappa \mathrm{B}$ binding motif was found in the iel promoter region. EMSA indicated that the recombinant RHD bound to the putative NF- $\kappa B$ site within the iel promoter region. A transactivity assay demonstrated that LvRelish could increase ie1 promoter activity in S2 cells. These results showed that LvRelish transactivated WSSV ie1 gene expression, and contributed to its high promoter activity. Further transactivation assays showed that WSSV IE1 protein expression upregulated the promoter activities of WSSV iel gene, as well as AMP genes (Figure 1). These results suggested that WSSV might annex the shrimp NF$\kappa \mathrm{B}$ pathway to enhance the expression of viral immediate-early genes [112].

Through whole genome sequence assay, wsv449 was found with 15.7 19.4\% identity to Tube, which was an important component of the insect Toll pathway. Further research showed that wsv 449 activated promoters of Toll pathway-controlled AMPs. Therefore, wsv449 has a similar function with host Tube in activating the NF-kB pathway. A promoter screening suggested that the promoter activities of ie1, wssv303 and wssv371 could be highly induced by the shrimp NF-kB family protein LvDorsal, as well as wsv449 [1].

\section{Shrimp IMD-Relish pathway upregulated expression of ten WSSV genes}

In the RNAi experiment, it was found that L. vannamei were resistant to WSSV infection when knock-down LvIKK $\beta$ or LvIKKe. The authors hypothesized that IKK-NF- $\kappa B$ signaling pathway modulating viral genes expression was required for successful infection with WSSV. A reporter gene assays with 147 WSSV genes screening revealed that the wsv051, wsv059, wsv069, wsv083, wsv090, wsv107, wsv244, wsv303, wsv371 and wsv445 promoters could be activated by LvIKK $\beta$ or LvIKKe in Drosophila S2 cells [55].

\section{Shrimp STAT activated the promoter of WSSV ie1}

Although the JAK/STAT signaling pathway is usually involved in antiviral defense, recent study suggested that it might be annexed by WSSV to enhance the expression of a viral immediate early gene in infected shrimps. Shrimp STAT belonged to the ancient STAT family, and the presence of the functional domains suggested that shrimp STAT shares similar functions and regulating mechanisms with the wellknown STATs isolated from model organisms. Shrimp STAT showed a decreased transcription level after WSSV infection, but increased level of phosphorylated (activated) STAT in the lymphoid organ. It was also showed that STAT was translocated from the cytoplasm to the nucleus and activated, in a primary culture of lymphoid organ cells derived 


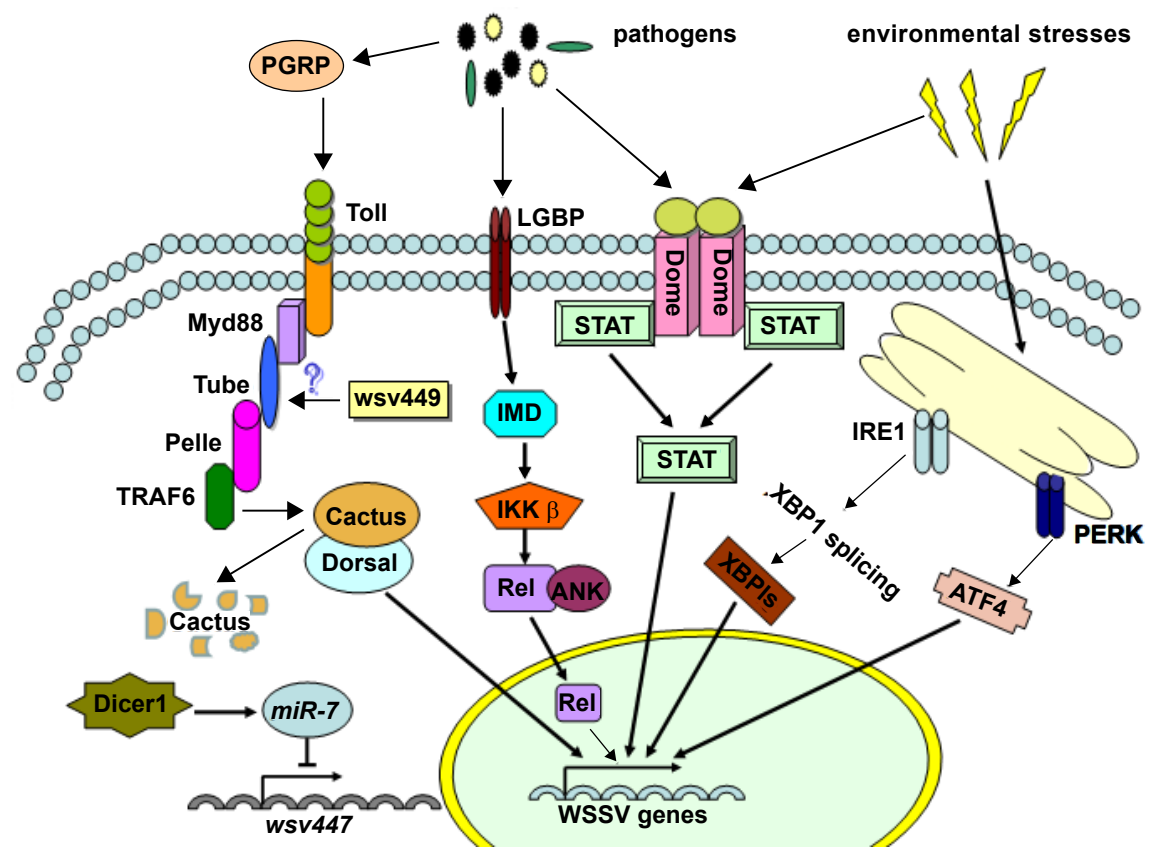

Figure 1: WSSV IE1 protein expression upregulated the promoter activities of WSSV ie1 gene, as well as AMP genes.

from WSSV-infected shrimp [2]. This result suggested that shrimp STAT was activated by WSSV.

Via a series of deletion and mutation assays, an element containing STAT binding motif was found to be important for the full level of WSSV ie1 promoter activity. PmSTAT bound to this element was detected by EMSA. It also found that in WSSV-infected P. monodon, levels of activated PmSTAT were higher than that in WSSV-free $P$. monodon. And increasing the level of rPmSTAT resulted in dosedependent increases the iel promoter activity. It was concluded that WSSV successfully annexed a putative shrimp defense mechanism to enhance the expression of viral immediate-early genes [113].

\section{RNAi pathway and WSSV genes regulation}

RNAi plays an important role in fine-tuning virus-host interactions via gene expression, which guided by miRNAs. Increasing evidence suggests that viral and cellular miRNAs are involved in virus infection. In M. japonicus miR-7 was found to be upregulated in response to WSSV infection. Shrimp miR-7 could target the 3'UTR of wsv477, suggesting that miR-7 might involve in viral DNA replication (Figure 1). Synthesized miR-7 could significantly decreased the expression level of the fluorescent construct bearing the 3'UTR of wsv477 in insect High Five cells, and that could be rescued by miR-7 blocking. In vivo, synthesized miR-7 injection would reduce the numbers of WSSV genome copies/mg gills about 1,000-fold at 72 and $96 \mathrm{~h}$ compared to the control. Besides, blocking of endogenous miR-7 by AMO-miR-7 led to about 10-fold increases of WSSV genome copies/mg gills in WSSVinfected M. japonicus comparing with the control WSSV only [114]. Thus these results indicated that M. japonicus miRNAs roled in hostvirus interactions by targeting the viral early gene. 35 miRNAs were identified, and a correlation of WSSV infection with the expression levels of 22 miRNAs was discovered in M. japonicus [115].

On the other hand, based on WSSV miRNA microarray and northern blot analyses, WSSV was proved to have the capacity encoding 40 viral miRNAs, which was about 360 times greater than that of human genome in content. The egregious high content of viral miRNAs of WSSV, suggested that WSSV miRNAs might greatly contribute to viral variability for dealing with host environment and responding. As reported, $80 \%$ of WSSV miRNAs were expressed during early stages of viral infection, which highlight their importance in initial infective processes. Besides host Drosha, Dicer1 and Agol, biogenesis of viral miRNAs was demonstrated to be dependent on viral miRNAs too, such as WSSV-miR211 and WSSV-miR212. These viral miRNAs were proved to be required for successful WSSV infection. Therefore, during WSSV infection, numerous viral genes were targeted by WSSV miRNAs [116].

The results as mentioned above indicate that the shrimp humoral immune responses which designed to clean pathogenic microorganisms were annexed by WSSV to enhance the expression of viral genes. It means that activated immune responses are essential to WSSV infection.

\section{Shrimp UPR and WSSV Genes Regulation}

\section{L. vannamei XBP1 transcriptional regulated wsv083}

After WSSV challenging, LvXBP1 was upregulated during the experiment and the percentage of the spliced form continuously declined after $18 \mathrm{~h}$ of infection. Besides, LvXBP1 upregulated wsv 083 in a UPRE-dependent manner [95]. Wsv083, an immediate early gene of WSSV, worked as a protein Ser/Thr kinase and inhibited the activity of focal adhesion kinase (FAK), involving in the processes of cell adhesion and spreading, which were crucial for invertebrate immune system [117]. It was suggested that wsv083 was important for WSSV to evade the host immune response. Knock-down LvXBP1 resulted in a lower cumulative mortality of L. vannamei under WSSV infection. Taken together, these results confirmed that the L. vannamei IRE1XBP1 may activated by WSSV and be annexed to serve the virus.

\section{L. vannamei ATF4 upregulation expression of wsv023}

ATF4 is the main transcription factor of PERK-eIF2 $\alpha$ pathway, 
and was reported to take part in viral genes regulation. For example, human ATF4 interacted with Tax and engaged in T-cell leukemia virus type 1 (HTLV-1) Tax protein activating viral transcription [118]. Based on the WSSV genome analysis, 15 genes (wsv023, wsv049, wsv064, wsv069, wsv138, wsv242, wsv256, wsv282, wsv303, wsv306, wsv313, wsv321, wsv343, wsv406 and wsv453) containing at least one putative ATF/CRE [TGACGT(G/C)A] within their promoter regions were selected. A luciferase reporter assay was performed to examine the relationship between transcription factors and these viral genes. Expression of pACB-LvATF4 significantly increased pGL3-wsv023 expression by approximately 10 -fold. When the ATF/CRE element of wsv023 promoter was mutated or deleted, the pGL3-wsv023 expression was significantly reduced by approximately $93 \%$ and $87 \%$ comparing to the wild type, respectively. The expression of pGL-wsv069 was also activated by LvATF4, increased by approximately 6 -fold. Taken together, these results suggested that in L. vannamei UPR signaling pathway transcription factors were important for WSSV infection [95].

\section{HSP70 and WSSV genes regulation}

High temperature $\left(32-33^{\circ} \mathrm{C}\right)$ has been shown to reduce mortality in WSSV infected shrimps, but the mechanism still remains unclear. It was found that in WSSV infected shrimps cultured at $32^{\circ} \mathrm{C}$, transcriptional levels of representative immediate early, early, and late genes of WSSV were initially higher than that at $25^{\circ} \mathrm{C}$. However, neither IE1 nor VP28 proteins were detected at $32^{\circ} \mathrm{C}$, suggesting that high temperature might inhibit WSSV protein synthesis. Two-dimensional gel electrophoresis analysis revealed two proteins, NAD-dependent aldehyde dehydrogenase (ALDH) and proteasome alpha 4 subunit (proteasome a4), were markedly up-regulated in WSSV-infected shrimps at $32^{\circ} \mathrm{C}$. RT-PCR analysis also showed hsp70 was up-regulated at $32^{\circ} \mathrm{C}$. When knocked-down ALDH or hsp70, shrimps challenging with WSSV became severely infected at $32^{\circ} \mathrm{C}$. While the proteasome $\alpha 4$ knock-down shrimps remained uninfected [87].

The above researches shown that UPR transcription factor XBP1s and LvATF4 could directly bind to WSSV genes and upregulate their expression, and the molecular chaperones ALDH and Hsp70 both play an important role in the inhibition of WSSV replication at high temperature. The relationship between UPR and WSSV infection is complicated. WSSV infection could trigger ER stress and in turn utilize UPR to expression IE gene, and then UPR inhibit WSSV protein synthesis.

\section{Conclusion and Perspective}

Similar to other eukaryotes, shrimp innate immunity and UPR are important for its survival. So far, TLRs pathway, IMD pathway, JAK-STAT pathway, and RNAi pathway have been identified in shrimp. Meanwhile, shrimp IRE1-XBP1 pathway and PERK- eIF2a pathway also have been investigated. More innate immunity relative pathways and UPR relative pathways will be found with the dramatic increase in sequence data. Considering their essentiality and necessity, shrimp innate immunity and UPR occupy important positions in the shrimp homoeostasis. They play important roles in innate immune responses to against various pathogens, such as bacterium, fungus and viruses, and they are also involved in environmental stress resisting. Generally speaking, viruses can be seen as either a pathogen or a kind of environmental stress. Among the shrimp viral pathogens, WSSV is well studied. An increasing evidences showed that WSSV successfully activated, and employed the shrimp innate immunity and UPR for its genes transcription.
Particularly noteworthy is the shrimp UPR. It has been reported that WSSV are widespread among the culture shrimp. Considering that environmental catastrophe, such as rainstorm and cold snap always following outbreak of WSS, it is possible that WSS outbreaks caused by environmental stress. Furthermore, UPR is not only critical for environmental stress resisting, but also cross-talk with several innate immunity signal pathways, such as TLRs pathway, autophagy pathway and apoptosis pathway [118-121]. Therefore, it seems that shrimp UPR play central role in the shrimp homoeostasis. Based on the previous research, we found the clues that WSSV could hijack and stimulate the shrimp innate immunity and UPR to facilitate its life cycle. To take advantage of the innate immunity responding or UPR, WSSV has to activate them first. However, we still have limited knowledge about that, even the functions of wsv023 and wsv083 in WSSV infection. There are already research teams that focus on the study of WSSV gene function. Further work on interaction between shrimp homoeostasis signal pathways and WSSV, especially the UPR and WSSV infection, would be helpful for developing new strategies to control shrimp disease, and their application in aquaculture would be of great significance $[89,122$ 126].

\section{Acknowledgements}

This research was supported by National Basic Research Program of China (973 program) under grant no. 2012CB114401; 'the Twelfth Five-Year-Plan' in National Key Technology R\&D program under grant no.2012BAD17B03; the National Science Fund for Young Scholars of China under grant no.31202017; the National Key Technology R\&D program under grant no. 2011BAD13B10; National Natural Science Foundation of China under grant No.U1131002, and China Agriculture Research System (47).

\section{References}

1. Wang PH, Gu ZH, Wan DH, Zhang MY, Weng SP, et al. (2011) The Shrimp NF-Kb Pathway is Activated By White Spot Syndrome Virus (WSSV) 449 to Facilitate the Expression of WSSV069 (le1), WSSV303 and WSSV371. PLos One 6: E24773.

2. Chen WY, Ho KC, Leu JH, Liu KF, Wang HC, et al. (2008) WSSV Infection Activates STAT In Shrimp. Dev Comp Immunol 32: 1142-1150.

3. Hoffmann JA (2003) The Immune Response of Drosophila. Nature 426: 33-38.

4. Schröder M, Kaufman RJ (2005) The Mammalian Unfolded Protein Response. Annu Rev Biochem 74: 739-789.

5. Shen X, Ellis RE, Lee K, Liu CY, Yang K, et al. (2001) Complementary Signaling Pathways Regulate the Unfolded Protein Response and are Required for $\mathrm{C}$. Elegans Development. Cell 107: 893-903.

6. Dragosits M, Stadlmann J, Graf A, Gasser B, Maurer M, et al. (2010) The Response to Unfolded Protein is Involved in Osmotolerance of Pichia Pastoris. BMC Genomics. 11: 207.

7. Marciniak SJ, Ron D (2006) Endoplasmic Reticulum Stress Signaling in Disease. Physiol. Rev. 86: 1133-1149.

8. Mori K, Kawahara T, Yoshida H, Yanagi H, Yura T (1996) Signalling From Endoplasmic Reticulum To Nucleus: Transcription Factor with a Basic-Leucine Zipper Motif Is Required for the Unfolded Protein-Response Pathway. Genes Cells 1: 803-817.

9. Cox JS, Walter P (1996) A Novel Mechanism for Regulating Activity of a Transcription Factor that Controls the Unfolded Protein Response. Cell 87: 391-404.

10. Sidrauski C, Walter $P$ (1997) The Transmembrane Kinase Ire1p is a SiteSpecific Endonuclease that Initiates Mrna Splicing in the Unfolded Protein Response. Cell 90: 1031-1039.

11. Walter P, Ron D (2011) The Unfolded Protein Response: From Stress Pathway To Homeostatic Regulation. Science 334: 1081-1086.

12. Harding HP, Calfon M, Urano F, Novoa I, Ron D (2002) Transcriptional and Translational Control in the Mammalian Unfolded Protein Response. Annu Rev Cell Dev Biol 18: 575-599. 
Citation: Chen Y, Li X, He J (2014) Recent Advances in Researches on Shrimp Immune Pathway Involved in White Spot Syndrome Virus Genes Regulation. J Aquac Res Development 5: 228 doi:10.4172/2155-9546.1000228

13. Kaufman RJ (1999) Stress Signaling from the Lumen of the Endoplasmic Reticulum: Coordination of Gene Transcriptional and Translational Controls. Genes Dev 13: 1211-1233

14. Ron D (2002) Translational Control in the Endoplasmic Reticulum Stress Response. J Clin Invest 110: 1383-1388.

15. Schröder M (2008) Endoplasmic Reticulum Stress Responses. Cell Mol Life Sci 65: 862-894.

16. Costa CZ, Da Rosa SE, De Camargo MM (2011) The Unfolded Protein Response: How Protein Folding Became a Restrictive Aspect for Innate Immunity and B Lymphocytes. Scand J Immunol 73: 436-448.

17. Gewandter JS, Staversky RJ, O'Reilly MA (2009) Hyperoxia Augments ERStress-Induced Cell Death Independent of Bip Loss. Free Radic Biol Med 47: 1742-1752.

18. Hassink GC, Zhao B, Sompallae R, Altun M, Gastaldello S, et al. (2009) The ER-Resident Ubiquitin-Specific Protease 19 Participates in the UPR and Rescues ERAD Substrates. EMBO Rep. 10: 755-761.

19. Madeo F, Kroemer G (2009) Intricate Links between ER Stress and Apoptosis. Mol Cell 33: 669-670

20. Belvin MP, Anderson KV (1996) A Conserved Signaling Pathway: The Drosophila Toll-Dorsal Pathway. Annu. Re. Cell Dev Bi 12: 393-416.

21. Kumagai Y, Takeuchi O, Akira S (2008) Pathogen Recognition by Innate Receptors. J Infect Chemother 14: 86-92.

22. Yang LS, Yin ZX, Liao JX, Huang XD, Guo CJ, et al. (2007) A Toll Receptor in Shrimp. Mol Immunol 44: 1999-2008.

23. Han-Ching Wang K, Tseng CW, Lin HY, Chen I, et al. (2010) Rnai Knock-Down of the Litopenaeus Vannamei Toll Gene (Lvtoll) Significantly Increases Mortality and Reduces Bacterial Clearance after Challenge with Vibrio Harveyi. Dev Comp Immunol 34: 49-58.

24. Labreuche Y, O'Leary NA, De La Vega E, Veloso A, Gross PS, et al. (2009) Lack of Evidence for Litopenaeus Vannamei Toll Receptor (Ltoll) Involvement in Activation of Sequence-Independent Antiviral Immunity in Shrimp. Dev Comp Immunol 33: 806-810.

25. Wang PH, Liang JP, Gu ZH, Wan DH, Weng SP, et al. (2012) Molecular Cloning, Characterization and Expression Analysis of Two Novel Tolls (Lvtoll2 And Lvtoll3) and Three Putative Spätzle-Like Toll Ligands (Lvspz1-3) From Litopenaeus Vannamei. Dev Comp Immunol 36: 359-371.

26. Arts JA, Cornelissen FH, Cijsouw T, Hermsen T, Savelkoul HF, et al. (2007) Molecular Cloning and Expression of a Toll Receptor in the Giant Tiger Shrimp, Penaeus Monodon. Fish Shellfish Immunol 23: 504-513.

27. Yang C, Zhang J, Li F, Ma H, Zhang Q, et al. (2008) A Toll Receptor From Chinese Shrimp Fenneropenaeus Chinensis is Responsive to Vibrio Anguillarum Infection. Fish Shellfish Immunol 24: 564-574.

28. Mekata T, Kono T, Yoshida T, Sakai M, Itami T (2008) Identification of Cdna Encoding Toll Receptor, Mitoll Gene from Kuruma Shrimp, Marsupenaeus Japonicus. Fish Shellfish Immunol 24: 122-133.

29. Hoffmann A, Neumann P, Schierhorn A, Stubbs MT (2008) Crystallization of Spatzle, a Cystine-Knot Protein Involved in Embryonic Development and Innate Immunity in Drosophila Melanogaster. Acta Crystallogr. Sect. F: Struct Biol Cryst Commun 64: 707-710.

30. Mulinari S, Häcker U, Castillejo-López C (2006) Expression and Regulation of Spätzle-Processing Enzyme. FEBS Letters 580: 5406-5410.

31. Shi XZ, Zhang RR, Jia YP, Zhao XF, Yu XQ, et al. (2009) Identification and Molecular Characterization of a Spatzle-Like Protein from Chinese Shrimp (Fenneropenaeus Chinensis). Fish Shellfish Immunol 27: 610.

32. Motshwene PG, Moncrieffe MC, Grossmann JG, Kao C, Ayaluru M, et al (2009) An Oligomeric Signaling Platform Formed by the Toll-Like Receptor Signal Transducers Myd88 and IRAK-4. J Biol L Chem 284: 25404-25411.

33. Lemaitre B, Hoffmann J (2007) The Host Defense of Drosophila Melanogaster Annu Rev Immunol 25: 697-743.

34. Bradley JR, Pober JS (2001) Tumor Necrosis Factor Receptor-Associated Factors (Trafs). Oncogene 20: 6482
35. Cao Z, Xiong J, Takeuchi M, Kurama T, Goeddel DV (1996) TRAF6 is a Signal Transducer for Interleukin-1. Nature 383:443-446.

36. Wang PH, Wan DH, Gu ZH, Deng XX, Weng SP, et al. (2011) Litopenaeus Vannamei Tumor Necrosis Factor Receptor-Associated Factor 6 (TRAF6) Responds To Vibrio Alginolyticu And White Spot Syndrome Virus (WSSV) Infection And Activates Antimicrobial Peptide Genes. Dev Comp Immunol 35: 105-114

37. Ip YT, Reach M, Engstrom Y, Kadalayil L, Cai H, et al. (1993) Dif a Dorsal -Related Gene that Mediates an Immune Response in Drosophila. Cell 75 753-763.

38. Li F, Wang D, Li S, Yan H, Zhang J, et al. (2010) A Dorsal Homolog (Fcdorsal) in the Chinese Shrimp Fenneropenaeus Chinensis is Responsive to Both Bacteria and WSSV Challenge. Dev Comp Immunol 34: 874-883.

39. Huang XD, Yin ZX, Jia XT, Liang JP, Ai HS, et al. (2010) Identification and Functional Study of a Shrimp Dorsal Homologue. Dev Comp Immunol 34: 107113.

40. Geisler R, Bergmann A, Hiromi Y, Nüsslein-Volhard C (1992) Cactus, A Gene Involved in Dorsoventral Pattern Formation of Drosophila, is Related to the $\mathrm{Ikb}$ Gene Family of Vertebrates. Cell 71: 613-621.

41. Li C, Chen YX, Zhang S, Lü L, Chen YH et al. (2012) Identification, Characterization, and Function Analysis of The Cactus Gene from Litopenaeus Vannamei. Plos One 7: E49711.

42. Wang D, Li F, Li S, Chi Y, Wen R, et al. (2012) An Ikb Homologue (Fccactus) in Chinese Shrimp Fenneropenaeus Chinensis. Dev Comp Immunol 39:352-62.

43. Akira S, Hoshino K (2003) Myeloid Differentiation Factor 88-Dependent and -Independent Pathways in Toll-Like Receptor Signaling. J Infect Dis187: S356363

44. Zhang S, Li CZ, Yan H, Qiu W, Chen YG, et al. (2012) Identification and Function of Myeloid Differentiation Factor 88 (Myd88) in Litopenaeus Vannamei. Plos One 7: E47038.

45. Wen R, Li F, Sun Z, Li S, Xiang J (2012) Shrimp Myd88 Responsive to Bacteria and White Spot Syndrome Virus. Fish Shellfish Immunol 34: 574-581.

46. Wang PH, Gu ZH, Wan DH, Zhu WB, Qu W, et al. (2013) Litopenaeus Vannamei Sterile-Alpha and Armadillo Motif Containing Protein (Lvsarm) is Involved in Regulation of Penaeidins and Antilipopolysaccharide Factors. Plos One 8: E52088.

47. Wang PH, Gu ZH, Wan DH, Zhu WB, Qu W, et al. (2013) Litopenaeus Vannamei Toll-Interacting Protein (Lvtollip) Is A Potential Negative Regulator of The Shrimp Toll Pathway Involved in The Regulation of the Shrimp Antimicrobial Peptide Gene Penaeidin-4 (PEN4). Dev Comp Immunol 40:266-277.

48. De Gregorio E, Spellman PT, Tzou P, Rubin GM, Lemaitre B (2002) The Tol and Imd Pathways are the Major Regulators of the Immune Response in Drosophila. EMBO J 21: 2568-2579.

49. Lemaitre B, Kromer-Metzger E, Michaut L, Nicolas E, Meister M, et al. (1995) A Recessive Mutation, Immune Deficiency (Imd), Defines Two Distinct Control Pathways In The Drosophila Host Defense. Proc Natl Acad Sci USA 92: 94659469.

50. Wang PH, Gu ZH, Huang XD, Liu BD, Deng XX, et al. (2009) An Immune Deficiency Homolog from the White Shrimp, Litopenaeus Vannamei, Activates Antimicrobial Peptide Genes. Mol Immunol 46: 1897-1904.

51. Hedengren M, Dushay MS, Ando I, Ekengren S, Wihlborg M, et al. (1999) Relish, a Central Factor in the Control of Humoralb But not Cellular Immunity in Drosophila. Mol Cell 4: 827-837.

52. Stöven S, Ando I, Kadalayil L, Engström Y, Hultmark D (2000) Activation of the Drosophila NF-Kb Factor Relish by Rapid Endoproteolytic Cleavage. EMBO Rep 1: 347-352.

53. Li F, Yan H, Wang D, Priya T, Li S, et al. (2009) Identification of a Novel Relish Homolog in Chinese Shrimp Fenneropenaeus Chinensis and Its Function in Regulating the Transcription of Antimicrobial Peptides. Dev Comp Immunol 33 1093-1101.

54. Huang XD, Yin ZX, Liao JX, Wang PH, Yang LS, et al. (2009) Identification and Functional Study of a Shrimp Relish Homologue. Fish Shellfish Immunol 27: $230-238$ 
Citation: Chen Y, Li X, He J (2014) Recent Advances in Researches on Shrimp Immune Pathway Involved in White Spot Syndrome Virus Genes Regulation. J Aquac Res Development 5: 228 doi:10.4172/2155-9546.1000228

Page 12 of 13

55. Wang PH, Gu ZH, Wan DH, Liu BD, Huang XD, et al. (2013) The Shrimp IKK-NF-K B Signaling Pathway Regulates Antimicrobial Peptide Expression and May be Subverted by White Spot Syndrome Virus to Facilitate Viral Gene Expression. Cell Mol Immunol 10: 423-436.

56. Darnell Jr JE, Kerr IM, Stark GR (1994) Jak-STAT Pathways and Transcriptional Activation in Response to Ifns and Other Extracellular Signaling Proteins. Science 264: 1415-1420.

57. Chen YH, Jia XT, Huang XD, Zhang S, Li M, et al. (2011) Two Litopenaeus Vannamei HMGB Proteins Interact with Transcription Factors Lvstat and Lvdorsal to Activate the Promoter of White Spot Syndrome Virus ImmediateEarly Gene le1. Mol Immunol 48: 793-799.

58. Pal-Bhadra M, Bhadra U, Birchler JA (2002) Rnai Related Mechanisms Affect Both Transcriptional and Posttranscriptional Transgene Silencing in Drosophila. Mol Cell 9: 315.

59. Shlomai A, Shaul Y (2003) Inhibition of Hepatitis B Virus Expression and Replication by RNA Interference. Hepatology 37: 764-770.

60. Labreuche Y, Warr GW (2012) Insights into the Antiviral Functions of the Rnai Machinery in Penaeid Shrimp. Fish Shellfish Immunol 34:1002-1010.

61. Unajak S, Boonsaeng V, Jitrapakdee S (2006) Isolation and Characterization of cDNA Encoding Argonaute, A Component of RNA Silencing in Shrimp (Penaeus Monodon). Comp Biochem Physiol B Biochem Mol Biol 145: 179-187.

62. Diederichs S, Haber DA (2007) Dual Role for Argonautes in Microrna Processing and Posttranscriptional Regulation of Microrna Expression. Cell 131: 1097-1108.

63. Dechklar M, Udomkit A, Panyim S (2008) Characterization of Argonaute Cdna from Penaeus Monodon and Implication of lits Role in RNA Interference. Biochem Biophys Res Commun 367: 768-774.

64. Huang T, Zhang $X$ (2012) Contribution of the Argonaute-1 Isoforms to Invertebrate Antiviral Defense. Plos One 7: E50581.

65. Phetrungnapha A, Panyim S, Ongvarrasopone C (2013) Penaeus Monodon Tudor Staphylococcal Nuclease Preferentially Interacts With N-Terminal Domain Of Argonaute-1. Fish Shellfish Immunol 34: 875-884.

66. Ketting RF, Fischer SE, Bernstein E, Sijen T, Hannon GJ, et al. (2001) Dicer Functions In RNA Interference and in Synthesis of Small RNA Involved in Developmental Timing in C. Elegans. Genes Dev 15: 2654-2659.

67. Lee YS, Nakahara K, Pham JW, Kim K, He Z, et al. (2004) Distinct Roles for Drosophila Dicer-1 and Dicer-2 in the Sirna/Mirna Silencing Pathways. Cell 117: 69-82

68. Su J, Oanh DT, Lyons RE, Leeton L, Van Hulten MC, et al. (2008) A Key Gene of the RNA Interference Pathway in the Black Tiger Shrimp, Penaeus Monodon: Identification and Functional Characterisation of Dicer-1. Fish Shellfish Immunol 24: 223-233.

69. Yao X, Wang L, Song L, Zhang H, Dong C, et al. (2010) A Dicer-1 Gene From White Shrimp Litopenaeus Vannamei: Expression Pattern in the Processes of Immune Response and Larval Development. Fish Shellfish Immunol 29: 565570.

70. Chen YH, Jia XT, Zhao L, Li CZ, Zhang S, et al. (2011) Identification and Functional Characterization of Dicer2 and Five Single VWC Domain Proteins of Litopenaeus Vannamei. Dev Comp Immunol 35: 661-671.

71. Li X, Yang L, Jiang S, Fu M, Huang J, et al. (2013) Identification and Expression Analysis of Dicer2 in Black Tiger Shrimp ( Penaeus Monodon) Responses to Immune Challenges. Fish Shellfish Immunol 35:1-8.

72. Wang S, Liu N, Chen AJ, Zhao XF, Wang JX (2009) TRBP Homolog Interacts with Eukaryotic Initiation Factor 6 (Eif6) in Fenneropenaeus Chinensis. J Immunol 182: 5250-5258

73. Wang S, Chen AJ, Shi LJ, Zhao XF, Wang JX (2012) TRBP and Eif6 Homologue in Marsupenaeus Japonicus Play Crucial Roles in Antiviral Response. Plos One 7: E30057.

74. Yang L, Li X, Huang J, Zhou F, Su T, et al. (2012) Isolation and Characterization of Homologous TRBP Cdna for RNA Interference in Penaeus Monodon. Fish Shellfish Immunol 34: 704-711.

75. Sabin LR, Zhou R, Gruber JJ, Lukinova N, Bambina S, et al. (2009) Ars2
Regulates Both Mirna-and Sirna-Dependent Silencing and Suppresses RNA Virus Infection in Drosophila. Cell 138: 340-351.

76. Chen YH, Zhao L, Jia XT, Li XY, Li CZ, et al. (2012) Isolation and Characterization of Cdnas Encoding Ars2 and Pasha Homologues, Two Components of the RNA Interference Pathway in Litopenaeus Vannamei. Fish Shellfish Immunol 32: 373-380.

77. Johnson GL, Lapadat R (2002) Mitogen-Activated Protein Kinase Pathways Mediated by ERK, JNK, and P38 Protein Kinases. Science 298: 1911-1912.

78. Yan H, Zhang S, Li CZ, Chen YH, Chen YG, et al. (2013) Molecular Characterization and Function of a P38 MAPK Gene from Litopenaeus Vannamei. Fish Shellfish Immunol 34:1421-1431.

79. De Gregorio E, Spellman PT, Tzou P, Rubin GM, Lemaitre B (2002) The Toll and Imd Pathways are the Major Regulators of the Immune Response in Drosophila. EMBO J 21: 2568-2579.

80. Gueguen Y, Garnier J, Robert L, Lefranc MP, Mougenot I, et al. (2006) Penbase, the Shrimp Antimicrobial Peptide Penaeidin Database: SequenceBased Classification and Recommended Nomenclature. Dev Comp Immuno 30: 283-288.

81. Kang CJ, Xue JF, Liu N, Zhao XF, Wang JX (2007) Characterization and Expression of a New Subfamily Member of Penaeidin Antimicrobial Peptides (Penaeidin 5) from Fenneropenaeus Chinensis. Mol Immunol 44: 1535-1543.

82. Tanaka S, Nakamura T, Morita T, Iwanaga S (1982) Limulus Anti-LPS Factor: An Anticoagulant which Inhibits the Endotoxin Mediated Activation of Limulus Coagulation System. Biochem Biophys Res Commun 105: 717-723.

83. Liu FS, Liu YC, Li FH, Dong, B, Xiang JH (2005) Molecular Cloning and Expression Profile of Putative Antilipopolysaccharide Factor in Chinese Shrimp (Fenneropenaeus Chinensis). Mar Biotechnol 7: 600-608.

84. Relf JM, Chisholm JR., Kemp GD, Smith VJ (1999) Purification and Characterization of a Cysteine-Rich 11.5-Kda Antibacterial Protein from the Granular Haemocytes of the Shore Crab, Carcinus Maenas. Eur J Biochem 264: 50-357.

85. Chen A, He N, Xu X (2008) Mj-DWD, A Double WAP Domain-Containing Protein with Antiviral Relevance in Marsupenaeus Japonicus. Fish Shellfish Immunol 25: 775-781.

86. Jiang S, Qiu L, Zhou F, Huang J, Guo Y, Yang K (2009) Molecular Cloning and Expression Analysis of a Heat Shock Protein (Hsp90) Gene from Black Tiger Shrimp (Penaeus Monodon). Mol Biol Rep 36: 127-134.

87. Lin YR, Hung HC, Leu JH, Wang HC, Kou GH, et al. (2011) The Role of Aldehyde Dehydrogenase and Hsp70 in Suppression of White Spot Syndrome Virus Replication at High Temperature. J Virol 85: 3517-3525.

88. Luana W, Li F, Wang B, Zhang X, Liu Y, et al. (2007) Molecular Characteristics and Expression Analysis of Calreticulin in Chinese Shrimp Fenneropenaeus Chinensis. Comp Biochem Physiol B Biochem Mol Biol 147: 482-491.

89. Ren Q, Zhou J, Sun SS, Kang CJ, Zhao XF, et al. (2011) Molecular Cloning and Expression Pattern Analysis of Two Novel Disulfide Isomerases in Shrimp. Comp Biochem Physioi C Toxicol Pharmacol 153: 301-309.

90. Visudtiphole $V$, Watthanasurorot $A$, Klinbunga $S$, Menasveta $P$, Kirtikara $K$ (2010) Molecular Characterization of Calreticulin: A Biomarker for Temperature Stress Responses of The Giant Tiger Shrimp Penaeus Monodon. Aquaculture 308, Supplement 1: S100-S108.

91. Soñanez-Organis JG, Peregrino-Uriarte AB, Gómez-Jiménez S, López-Zavala A, Forman HJ, et al. (2009) Molecular Characterization of Hypoxia Inducible Factor-1 (HIF-1) From The White Shrimp Litopenaeus Vannamei and TissueSpecific Expression Under Hypoxia. Comp Biochem Physiol C Pharmacol Toxicol Endocrinol 150: 395-405.

92. Li T, Brouwer M (2007) Hypoxia-Inducible Factor, Gshif, of the Grass Shrimp Palaemonetes Pugio: Molecularcharacterization and Response to Hypoxia. Comp Biochem Physiol B Biochem Mol Biol 147: 11-19.

93. Vargas-Albores F, Martínez-Martínez A, Aguilar-Campos J, Jiménez-Vega F (2009) The Expression of Protein Disulfide Isomerase from Litopenaeus Vannamei Hemocytes is Regulated by Bacterial Inoculation. Comp Biochem Physiol D Genomics. Proteomics 4: 141-146.

94. Chen YH, Zhao L, Pang LR, Li XY, Weng SP, et al. (2012) Identification and Characterization of Inositol-Requiring Enzyme-1 and X-Box Binding Protein 
Citation: Chen Y, Li X, He J (2014) Recent Advances in Researches on Shrimp Immune Pathway Involved in White Spot Syndrome Virus Genes Regulation. J Aquac Res Development 5: 228 doi:10.4172/2155-9546.1000228

1. Two Proteins Involved in the Unfolded Protein Response of Litopenaeus Vannamei. Dev Comp Immunol 38: 66-77.

95. Li XY, Pang LR, Chen YG, Weng SP, Yue HT, et al. (2013) Activating Transcription Factor 4 And $X$ Box Binding Protein 1 of Litopenaeus Vanname Transcriptional Regulated White Spot Syndrome Virus Genes Wsv023 And Wsv083. PLos One 8: E62603.

96. Lindquist S, Craig E (1988) The Heat-Shock Proteins. Annu Rev Genet 22: 631-677.

97. Gross P, Bartlett T, Browdy C, Chapman R, Warr G (2001) Immune Gene Discovery by Expressed Sequence Tag Analysis of Hemocytes and Hepatopancreas in the Pacific White Shrimp, Litopenaeus Vannamei, and The Atlantic White Shrimp. L Setiferus Dev Comp Immunol 25: 565-577.

98. Zhou J, Wang WN, He WY, Zheng Y, Wang L, et al. (2010) Expression of HSP60 and HSP70 in White Shrimp, Litopenaeus Vannamei in Response to Bacterial Challenge. J Invertebr Pathol 103: 170-178.

99. Huang WJ, Leu JH, Tsau MT, Chen JC, Chen LL (2011) Differential Expression of Lvhsp60 in Shrimp in Response to Environmental Stress. Fish Shellfish Immunol 30: 576-582.

100.Wu R, Sun Y, Lei L, Xie S (2008) Molecular Identification and Expression of Heat Shock Cognate 70 (HSC70) in the Pacific White Shrimp Litopenaeus Vannamei. Mol Biol 42: 234-242.

101. Luan W, Li F, Zhang J, Wen R, Li Y, Xiang J (2010) Identification of a Nove Inducible Cytosolic Hsp70 Gene in Chinese Shrimp Fenneropenaeus Chinensis and Comparison of Its Expression with The Cognate Hsc70 Under Different Stresses. Cell Stress Chaperon 15: 83-93.

102. Li F, Luan W, Zhang C, Zhang J, Wang B, et al. (2009) Cloning of Cytoplasmic Heat Shock Protein 90 (Fchsp90) from Fenneropenaeus Chinensis and its Expression Response to Heat Shock and Hypoxia. Cell Stress Chaperon 14: 161-172.

103. Huang PY, Kang ST, Chen WY, Hsu TC, Lo CF, et al. (2008) Identification of the Small Heat Shock Protein, HSP21, of Shrimp Penaeus Monodon and the Gene Expression of HSP21 is Inactivated Aafter White Spot Syndrome Virus (WSSV) Infection. Fish Shellfish Immunol 25: 250-257.

104. Rungrassamee W, Leelatanawit $R$, Jiravanichpaisal $P$, Klinbunga $S$ Karoonuthaisiri N (2010) Expression and Distribution of Three Heat Shock Protein Genes Under Heat Shock Stress and Under Exposure to Vibrio Harveyi in Penaeus Monodon. Dev Comp Immunol 34: 1082-1089.

105. Clegg JS, Willsie JK, Jackson SA (1999) Adaptive Significance of a Small Heat Shock/A-Crystallin Protein (P26) in Encysted Embryos of the Brine Shrimp, Artemia Franciscana. Am Zool 39: 836-847.

106. Danwattananusorn T, Fagutao FF, Shitara A, Kondo H, Aoki T, et al. (2011) Molecular Characterization and Expression Analysis of Heat Shock Proteins 40, 70 and 90 from Kuruma Shrimp Marsupenaeus Japonicus Fish Sci 77 : 929-937.

107.Rao RV, Peel A, Logvinova A, Del Rio G, Hermel E, et al. (2002) Coupling Endoplasmic Reticulum Stress to the Cell Death Program: Role of the ER Chaperone GRP78. FEBS Lett 514: 122.

108. Ahearn GA, Mandal PK, Mandal A (2004) Calcium Regulation in Crustaceans During the Molt Cycle: A Review and Update. Comp Biochem Physiol A Mo Integr Physiol 137: 247-257.

109. Michalak M, Milner R, Burns K, Opas M (1992) Calreticulin. Biochem J 285 681.

110. Visudtiphole V, Watthanasurorot A, Klinbunga S, Menasveta P, Kirtikara K (2010) Molecular Characterization of Calreticulin: A Biomarker for Temperature Stress Responses of the Giant Tiger Shrimp Penaeus Monodon. Aquaculture 308: S100-S108.
111. Liu WJ, Chang YS, Wang CH, Kou GH, Lo CF (2005) Microarray and RTPCR Screening for White Spot Syndrome Virus Immediate-Early Genes in Cycloheximide-Treated Shrimp. Virology 334: 327-341.

112. Huang XD, Zhao L, Zhang HQ, Xu XP, Jia XT, et al. (2010) Shrimp NF-Kb Binds to the Immediate-Early Gene le1 Promoter of White Spot Syndrome Virus and Upregulates its Activity. Virology 406: 176-180.

113. Liu WJ, Chang YS, Wang AHJ, Kou GH, Lo CF (2007) White Spot Syndrome Virus Annexes a Shrimp STAT to Enhance Expression of the Immediate-Early Gene le1. J Virol 81: 1461-1471.

114. Huang T, Zhang $X$ (2012) Functional Analysis of a Crustacean Microrna in Host-Virus Interactions. J Virol 86: 12997-13004.

115. Ruan L, Bian X, Ji Y, Li M, Li F, et al. (2011) Isolation and Identification of Novel Micrornas from Marsupenaeus Japonicus. Fish Shellfish Immunol 31 334-340.

116. He Y, Zhang X (2012) Comprehensive Characterization of Viral Mirnas Involved in White Spot Syndrome Virus (WSSV) Infection. RNA Biol 9: 10191029

117. Lu H, Ruan L, Xu X (2011) An Immediate-Early Protein of White Spot Syndrome Virus Modulates The Phosphorylation of Focal Adhesion Kinase of Shrimp. Virology 419: 84-89.

118. Gachon F, Thebault S, Peleraux A, Devaux C, Mesnard JM (2000) Molecular Interactions Involved in The Transactivation of the Human T-Cell Leukemia Virus Type 1 Promoter Mediated by Tax and CREB-2 (ATF-4). Mol Cell Biol 20: $3470-3481$

119. Gough NR (2010) UPR To TLR Connection. Sci Signal 3: Ec124

120. Yorimitsu T, Nair U, Yang Z, Klionsky DJ (2006) Endoplasmic Reticulum Stress Triggers Autophagy. J Biol Chem 281: 30299-30304

121. Szegezdi E, Logue SE, Gorman AM, Samali A(2006) Mediators of Endoplasmic Reticulum Stress-Induced Apoptosis. EMBO Rep 7: 880-885

122. Assavalapsakul W, Panyim S (2012) Molecular Cloning and Tissue Distribution of the Toll Receptor in the Black Tiger Shrimp, Penaeus Monodon. Genet Mol Res 11: 484-493.

123. Labreuche Y, Veloso A, De La Vega E, Gross PS, Chapman RW, Browdy CL, Warr GW (2010) Non-Specific Activation of Antiviral Immunity and Induction of RNA Interference may Engage the Same Pathway in the Pacific White Leg Shrimp Litopenaeus Vannamei. Dev Comp Immunol 34: 1209-1218.

124. Huang T, Xu D, Zhang X (2012) Characterization of Shrimp Drosha in Virus Infection. Fish Shellfish Immunol 33: 575-581.

125. Lo WY, Liu KF, Liao IC, Song YL (2004) Cloning and Molecular Characterization of Heat Shock Cognate 70 from Tiger Shrimp (Penaeus Monodon). Cell Stress Chaperon 9: 332

126. Talakhun W, Roytrakul S, Phaonakrop N, Kittisenachai S, Khamnamtong B, et al. (2012) Identification of Reproduction-Related Proteins and Characterization of the Protein Disulfide Isomerase A6 Cdna in Ovaries of the Giant Tiger Shrimp Penaeus Monodon. Comp Biochem Physiol Part D Genomics Proteomics 7 : 180-190. 